\title{
O lugar da educação na obra de Gaston Bachelard
}

Luzia Batista de Oliveira Silva ${ }^{1}$

\section{Introdução}

Inicio este texto a partir da entrevista, na inauguração do Canal Bachelard Brasil, respondendo à pergunta do criador do canal, Gabriel Kafure da Rocha: Por que Bachelard e qual o lugar que a educação ocupa em sua obra? O que significa afirmar Bachelard educador? Tento responder afirmativamente essas questões, ainda que de maneira simples, numa alusão à sua obra, Filosofia do não - por que não Bachelard? E por que não Bachelard educador?

É sempre um movimento de fortalecimentos e descobertas de novos aprendizados ao ler, falar e trocar ideias sobre Bachelard. Por isso, destacaremos, nos aparatos da filosofia, nossa primeira tarefa; a segunda tarefa será inseri-lo nos aparatos da educação. Sua Filosofia oferece material para resistências e representa o frescor que a academia, de certa forma, perdeu e não sabe mais como recuperar. Bachelard foi pensador crítico, de ironias finas e sutis, e por vezes, desconcertante. Seu pensamento é liberador e ousaria mesmo dizer, libertário, fazendo compreender que, no processo de formação humana, é relevante tanto o autoconhecimento quanto o conhecimento para viver numa sociedade contraditória e que nem sempre trabalha para conciliar saberes. Por isso, como educador da ciência e da filosofia, dialogou a respeito de outras áreas do conhecimento humano, num mundo em que perdemos, todo dia, a capacidade de nos fazer "esperançar", no sentido de Paulo Freire (1997).

Bachelard é mestre de saberes e sabores, de sensibilidades e sabedorias para além do mundo da academia. Mundo, muitas vezes, engessado por rótulos, preferências subjetivas e grupais, viventes do Tempo das tribos (MAFFESOLI, 1998), não só dos jovens, mas, numa alusão, a tribos acadêmicas sempre fechadas, restritas àqueles que delas fazem parte.

O pensamento - ainda Bachelard - que desnuda sentimentos, olhares, olfatos, paladares, audições, tatos nos lembra que é possível sonhar acordado, como a criança em seus devaneios

\footnotetext{
1 Docente no Programa de Pós-Graduação Stricto Sensu em Educação - PPGSSE/USF, São Paulo, email lubaos@gmail.com / luzia.silva@usf.edu.br.
}

Periódico Horizontes - USF - Itatiba, SP - Brasil - e021043 
ou como o adulto nos seus momentos oníricos. Pensamento que nos alerta para o fato de que é fundamental sonhar antes de pensar, por isso, nos faz pensar nos verbos ver, ouvir, tocar, cheirar, saborear, pensar, sentir o pensamento como partes da filosofia do ser humano em contato com a natureza, em contato com a sua natureza, muitas vezes, adormecida, ignorada, relegada a segundo plano.

Bachelard atesta que o cogito de um sonhador é povoado de imagens, de miragens, de devaneios e onirismos, de mundos conhecidos e desconhecidos, criados e descobertos; que é possível despertar para sentir o sabor das coisas, ver as cores do mundo, porque, numa vida apressada, não prestamos mais a devida atenção nas coisas, como não prestamos mais atenção em nós mesmos, nos nossos sentimentos e nas outras pessoas.

Bachelard, porque, fundamentalmente, a distração, numa sociedade capitalista como a nossa, virou sinônima de cansaço, de melancolia. Bachelard, porque nos falta mar com suas cores, odores e ondas, para o amar o mundo, amar o destino, como em Nietzsche (2001); falta o rio de Heráclito, o rio da vida e da morte, da fome e da saciedade, o rio de Bachelard, em que observar as cenas do pássaro Martin-pescador, no rio de Bar-Sur-Aube (cidade onde ele nasceu), era algo inesquecível; nos falta terra para pisar, paisagens e paragens para determos nossos olhares de viventes; falta refúgio para o espírito cansado e atribulado num mundo em que a natureza não é mais pensada, sentida ou exaltada, a natureza em nós desbotou, desencantou-se do ser humano.

Por que Bachelard? Porque Bachelard é atualíssimo, e cada leitura de sua obra é uma leitura de mundos habitados e sonhados. Bachelard, porque nos desperta do sono dogmático, ideológico e coloca seu leitor na rota dos sentimentos poéticos da vida para ver o mundo com olhos de esperança, a natureza como a mãe acolhedora e o cosmos como o destino final.

\section{Gaston Bachelard educador}

Pierre Quillet (1977, p.19) pontua que "é preciso lembrar que um curso ou uma conferência de Bachelard são essencialmente um festival Bachelard". O encontro que tivemos sobre o pensamento de Bachelard, na criação do Canal Bachelard Brasil, foi, sem dúvida, um "festival Bachelard", com sorrisos leves, apontamentos instigantes, partilhas, experiências, 
momentos ensinantes e calor suficiente para aquecer a vida triste em meio à pandemia do coronavírus que assola o mundo e causa temor, cansaço, isolamento humano mais que isolamento social.

A preocupação de Bachelard com a educação, a partir da formação do ser humano, deixa sobressair, em sua obra, o caráter pedagógico, a ponto de Léon Brunschvicg lhe perguntar o porquê de sua preocupação pedagógica no ensino da ciência e da poesia, e ele lhe responder na obra O Racionalismo Aplicado (1977), que provavelmente ele era mais professor que filósofo. Pode-se discutir o sentido dessa resposta, que não é simples e nem complexa, é, isto sim, uma resposta reveladora de um educador potente que se compraz com a troca que pode gerar muitos aprendizados, atestando disposição para o diálogo no campo das ciências exatas e humanas.

Sua proposta e provação de uma Pedagogia da horizontalidade apontam para a necessidade de uma pedagogia capaz de devolver à razão humana sua função de turbulência e agressividade, sendo possível, por isso, aprender e conquistar autonomia no processo formativo, destituindo a passividade, a indiferença, a cegueira e a ignorância de educadores e educandos (JAPIASSU, 1993; SILVA, 2018).

No que tange ao ensino de Bachelard, Quillet (1977) destaca que o ensino de Bachelard não pode ser considerado vulgarização, algo insignificante, nem pedagogia no sentido estrito do termo, visto que ele não busca formar e nem informar seus leitores e discentes, mas que o seu ensino se constitui em algo que que não se deixa confiscar pela vulgarização, escoamento líquido, ascetismo ou recalcamento ativo, marcado por traços de liberação sublimada, isto é, ascensão, elevação do ser humano. O mestre deve adotar uma conduta amável e paciente, mostrando-se capaz de ensinar e aprender com o que ensina. Quillet (1977) adverte que essa regra também se aplica aos filósofos, e a não observância dela reforça obstáculos à liberdade de pensamento daquele que se educa com o que ensina.

Ao educador, compete saber educar com estabilidade e equilíbrio e quando sentir que lhe faltam tais atributos, deve abdicar do ensino, porque "Ainda que seja muito instruído, sem uma estabilidade (shifting character) em exercício, ele não pode dar a experiência da abertura" (BACHELARD, 1978, p.128).

Filósofo é aquele que desconstrói instruções, rotas e rótulos na escola e na vida; é aquele que descarta metodologias e métodos inúteis de aprendizagem que separam razão e 
sensibilidade, que colocam mundos paralelos que nunca se tocam e nem se complementam. Bachelard nos ensinará, de acordo com Quillet (1977, p.9),

[...] a ler como jamais outro professor fez, com uma incredulidade vigilante diante das histórias contadas e o mais prudente discernimento para com material imaginário investido na empresa da linguagem, com a segurança do perito que distingue o verdadeiro do falso, quando o próprio autor se engana.

Pensador inovador, olhar curioso de filósofo hermeneuta, de olhar atento e curioso para a psicanálise freudiana, como o complexo de Édipo (SILVA, 2013); pensador inovador que tece novas considerações no que diz respeito à educação; pensador inovador que traz os complexos de Prometeu e o de Cassandra (SILVA, 2013); o primeiro, por considerar que, no processo educacional, o aluno deve superar os pais e os mestres e o segundo, por denunciar as falsas profecias do educador contra aquele a quem ele educa e que deve, sabidamente, superá-lo.

No que diz respeito aos complexos, Bachelard compreendeu sua estereotipia em vários campos do conhecimento humano (SILVA, 2013). Por isso, ao investigarmos, por muito tempo, suas obras, foi possível identificar cerca de sessenta e nove complexos, estereótipos, porque, mesmo quando identificados, no campo da ciência, eles se assemelham, no âmbito da estética, da imaginação criadora, a imagens fantasiosas, exageradas, rotuladoras e ou deformativas.

Bachelard educador coloca em xeque a força da palavra profética e incentivadora do educador. Na obra a Psicanálise do fogo, afirma que é fundamental o aprendizado que liberta a pessoa para que ela possa se voltar contra os mestres que pensam que educam, mas que, na verdade, mantêm o espírito deformativo. É preciso se educar para se opor - se necessário - ao sistema escolar, porque é fundamental trabalhar contra o que há de negativo, de bloqueio, de entrave, de autoritarismo nos educadores, a fim de superarmos obstáculos postos e interpostos, ser mais que o seu mestre, ser "si próprio" no sentido nietzschiano, filósofo, para quem ele tem um olhar carregado de admiração e aprovação, um Nietzsche destruidor de rótulos e desmistificador de moralismos.

Bachelard sonhador de palavras, mas não será como pedagogo que abordará a infância, mas como autor de devaneios, por isso, insere a infância no contexto dos devaneios, mas não a trata apenas como um tema para os devaneios, porque "[...] os devaneios voltados para a infância é, pois, uma contribuição para a metafisica do tempo elegíaco. Afinal, esse tempo da elegia 
íntima, esse tempo de pesar que perdura é uma realidade psicológica" (BACHELARD, 1996, p.17).

Contrapõe-se a René Descartes por este considerar que "pensar, querer, amar, sonhar são somente uma atividade do seu espírito [...]" (BACHELARD, 1996, p.22). O sonhador de devaneios é aquele que rompe o pensar para alcançar o onirismo, a fim de sonhar de olhos abertos e buscar a felicidade nas imagens do pensamento criativo.

Filósofo que defende um pensamento "aberto, setorial, dinâmico, militante", o que, segundo Pessanha, no prefácio da obra O direito de sonhar (1994, p.v), dificulta criar descendentes. Talvez seja mesmo difícil, mas é oportuno lembrar que Bachelard ganhou territórios e seguidores em muitos países. O Brasil, por exemplo, é um país que atesta esse cenário profícuo e fertilizador para suas ideias.

O estilo de Bachelard educador da infância é o "[...] estilo de elevação respeitador dos degraus do ser, da família e da ausência do outro, uma espécie de eternidade que imortaliza apenas a infância" (QUILLET, 1977, p.133). Por que todo esse cuidado do filósofo educador? Porque "a criança é um materialista nato... seus primeiros sonhos são sobre as substâncias orgânicas" (BACHELARD, 1989a, p.13). A criança é o ser que atesta a grandeza do mundo que nos cerca, que nos alimenta, nos encanta.

Quillet (1977) lembra a implicância de Bachelard com o elemento da ordem do pesado, o que não tem um ritmo, um dinamismo, um movimento veloz, que ele chamou de "o demônio do pesado" (QUILLET, 1977, p.142), simbolizando o peso da responsabilidade, da materialidade, contrariando a leveza que marca o espírito dinâmico, que se eleva como uma chama por sua própria leveza, estica o nosso ser, se eleva para além de qualquer subida, se do pesado, numa alusão, talvez, à poesia ascensional de Nietzsche, no Zaratustra (2011).

Em defesa de uma escola contínua - a "[...] escola que a ciência deve fundar. Assim, os interesses sociais serão definitivamente invertidos: a sociedade será feita pela escola, e não a escola pela sociedade" (BACHELARD, 1996, p.252). Uma escola capaz de gestar uma sociedade como se fosse uma escola e não a sociedade gestando a escola como se fosse uma sociedade, exemplo que não tem dado certo há muito tempo.

Educação, para Bachelard, é a educação em que se pode conquistar a autonomia para pensar e criar, autonomia que temos ou deveríamos ter para sonhar e trabalhar para efetivar uma educação para a desobediência - "Desobedecer a fim de alcançar a graça da razão, como a 
prova imediata e decisiva da autonomia"2 (JEAN, 1989, p.17). Ao mestre, cabe conduzir o aluno para que este abandone, de maneira lúcida, o onirismo da imaginação, e ao aluno, cabe desobedecer. Assim, nesse jogo entre mestre e educando, tem-se uma desobediência criadora, ou seja, tem-se o fortalecimento da virtude humana, a virtude de poder sonhar e poder pensar. Essa desobediência revela a leveza do espírito para sonhar e pensar, para liberar-se do pesado. Tem-se, com isso, uma pedagogia do devir, do vir-a-ser e do ser.

Recuperar no adulto um estado de infância não significa infantilizar-se ou apegar-se às lembranças da infância ou querer reviver a infância, mas valorizar a memória imaginária, aquela memória que nos permite reimaginar o nosso passado de maneira onírica, sem fixações ou desencadeamento de sofrimentos.

Uma pedagogia da razão pode contribuir para preservar a infância e a vitalidade de sua imaginação (JEAN, 1989). Trata-se de uma pedagogia primeira para o jardim da infância. Já a formação deve ser compreendida como formação do espírito científico e do espírito poético, o que significa que a formação contempla o ser humano em todas as idades e dimensões de sua vida (JEAN, 1989).

A infância pede uma educação no sentido de uma pedagogia que acontece quando o educador sabe fazer-se criança sem ser criança, quando sabe "se fazer de bobo" como recurso para compreender a si mesmo, para mostrar mais em vez de falar (JEAN, 1989). E "como seria bom termos um mestre silencioso ao invés de um mestre falante... quando se tem tanto para mostrar, por que falar? - a nossa fala diz mais de nós mesmos do que do outro..." (BACHELARD, 1977, p.30).

O educador é aquele que educa evitando diálogos psicologizantes, caracterizado como aquele que se porta como se estivesse numa entrevista psicológica; o educador não pode se portar como um analista, não pode se utilizar desse recurso, também porque esse recurso é uma evasão daquilo que deve ser trabalhado.

O educador é aquele que alimenta e se alimenta de uma filosofia do contra ou uma educação do contra: contra a simplicidade, a claridade e o saber que ignora a complexidade; contra uma ciência ensinada e uma técnica de leitura de manuais; contra o ensinar aquilo que já

\footnotetext{
2 "Desobedecer, escribe, para el que ha sido alcanzado por la gracia o por la razón, es la prueba inmediata y decisiva de la autonomía".
}

Periódico Horizontes - USF - Itatiba, SP - Brasil - e021043 
é conhecido, que não contribui com o pensamento cientifico; contra o ensino de imagens mortas, congeladas, estereotipadas; contra os pais e mestres autoritários; contra um educador/educação que deixa por conta do discente o próprio aprendizado e cruza os braços - o educador precisa superar a tradição e inovar, sem ignorar o rigor ou severidade justa, saber se relacionar consigo, com o outro, com os outros para se voltar contra "uma sociedade sem vida na qual somos livres de fazer tudo, mas onde não há nada para fazer" (BACHELARD, 1977, p.90); contra o peso de carregar os preconceitos do mundo, os obstáculos epistemológicos incompreendidos que nos colocam contra a ciência e instrução científica e contra o próprio aprendizado, impossibilitando a luta para ser livre e capaz de construir a própria autonomia.

A educação proposta pelo educador da ciência é a filosofia do contra que diz não à contemplação secular na filosofia e que já foi motivo de críticas por parte de Karl Marx, Nietzsche, uma filosofia contra uma posição passiva, contemplativa e nada prática, contra os exageros dialéticos como solução para todas as contradições do pensamento, contra os métodos facilitadores que substituem o pensar e o criar pela técnica, que funciona como molde para ser preenchido (JEAN, 1989).

Quillet (1977, p.11) considera que, contraditoriamente, "Bachelard foi um não escolar e profundamente escolar". Foi aquele que se colocou contra uma escolarização que não permite sonhar, aprender, mas apenas repetir conhecimentos estanques, uma educação que só tem experiência como reprodução das experiências. Por isso, cabe também ao mestre seguir sendo um aluno a fim de compreender a relação da criança, dos adolescentes e dos jovens com o conhecimento.

\section{Considerações finais}

Ao finalizar este ensaio, destaco o modo exemplar e educativo com que Bachelard analisa Os cantos de Maldoror, de Isidore Ducasse ${ }^{3}$ (BACHELARD, 1989b), numa tentativa de sensibilizar os seus leitores para o grito de ódio dado por Isidore Ducasse aos quatro cantos da escola; um grito de dor daquele que é jovem mas se sente confinado/prisioneiro de um espaço escolar; grito,

\footnotetext{
${ }^{3}$ Isidore Ducasse (1846-1870), poeta uruguaio que viveu na França, autor da obra: Os cantos de Maldoror, ficou conhecido pelo pseudônimo literário de Conde de Lautréamont.
}

Periódico Horizontes - USF - Itatiba, SP - Brasil - e021043 
enfim, daquele que é obrigado a repetir lições, ser reprimido o tempo todo, sofrer chacotas (como a da cabeça raspada), ser esquecido pela família, sentir-se vigiado e cobrado o tempo todo.

Ducasse é a expressão de uma contracultura em oposição à cultura escolar vigente, equivocada, austera e confinadora da vida, aquela que confisca a infância, a adolescência e a juventude; o seu grito é um grito contra o abuso e o autoritarismo no processo de escolarização; grito contra a escola como um cárcere, um sistema prisional de punições e favores; grito a favor daquele que se vê cerceado por todos os lados recebendo um tratamento severo que potencializa sua raiva na esperança de viver dias menos severos e sem a violência ele sofre todo o tempo. Enfim, seus revides expressam o sentimento de que querer viver pode significar querer atacar para viver, ou melhor, sobreviver (BACHELARD, 1989b). Ducasse se coloca contra um tempo de esvaziamento, de descontinuidade, um tempo de morte, de desacelaramento da vida em plena flor da idade. Daí, revida com um tempo de aceleramento, do não à morte que o atemoriza, um contra a morte para afirmação da vida, da sua vida tão enviesada, vilipendiada.

As forças imaginantes/devaneantes são forças que nos mobilizam para ações e sentimentos no contato com a matéria dos elementos - terra, água, fogo e ar. Essas forças imaginantes criam mundos poéticos, realidades paralelas, expressam nosso bem ou mal-estar no mundo.

O corpo, para Bachelard (1989a), é lugar de histórias, de memória, de educação. Destarte,

a primeira convicção calorosa é um bem-estar corporal. É na carne, nos órgãos, que nascem as imagens materiais primordiais. O rosto humano é, antes de tudo, o instrumento que serve para seduzir. Mirando-se, o homem prepara, aguça, lustra esse rosto, esse olhar, todos os instrumentos de sedução... (BACHELARD, 1989a, p.36)

Educador que ensinou que a poesia é um elemento educativo quando não se ignoram as várias faces de um mesmo problema, quando não se ignora a ambiguidade, a contradição, porque, no jogo dos opostos, existe vida e morte, sol e chuva, luz e escuridão, bem e mal, bom e ruim, forte e fraco, acordado e dormindo, riso e choro; na poesia da dor, existe sangue, morte, queda, abismo, martírio, infortúnio, desequilíbrio, violência, agressividade, selvageria; na poesia do rancor, existe violência, revide, agressividade, crueldade, maldade, orgulho ferido, covardia, desespero, suicídio; na poesia do amor, existe o riso leve e solto, o sorriso das coisas, da natureza, 
dos elementos; os astros revelam que "a lua, a noite, as estrelas lançam então, como flores, seus reflexos sobre o rio" (BACHELARD, 1989a, p.91). O poeta educador nos ensina que "a noite é uma substância... a noite é a matéria noturna" (1989a, p.105); que "o limo é a poeira da água, como o cinza é a poeira do fogo" (1989a, p.114); que "amar o universo infinito é dar um sentido material" (1989a, p.120) para a vida planetária; que "a grande fatalidade do mundo, a fome, pertence somente à terra; aqui, ela é prevenida, ignorada" (1989a, p.123). A água é a imagem do feminino, da mãe dadivosa, inamovível, do leite, do mel, do muco, cujas margens dos rios são seios intumescidos de leite, leite imaginário que entorpece a alma e o corpo e criam formas de expressar sentimentos, movimentos, tempos e espaços.

Gaston Bachelard nos lembra os cuidados que não podem ser esquecidos para com a criança e com a natureza, que a poética dos quatro elementos é vida que atesta a importância educativa do brincar, do devanear infantil e do onirismo do adulto.

O lugar da educação na universidade é identificado por sua afirmação de que ele se sentia mais professor que filósofo. Ensinar significa aprender com o que se ensina e a quem se ensina, e, deixando de lado as falsas modéstias na universidade, pode ser considerado um professor aquele que faz avançar a cultura do aluno, que se faz compreender pelo aluno, que identifica e acolhe os níveis de aprendizado daquele a quem educa.

\section{Referências}

BACHELARD, G. O racionalismo aplicado. Trad. Nathanael C. Caixeiro. Rio de Janeiro: Zahar, 1977.

BACHELARD, G. O novo espírito científico. In: PESSANHA, J. A. M (org.). A filosofia do não; o novo espírito científico; a poética do espaço. Trad. Remberto F. Kuhnen. São Paulo: Abril Cultural, 1978, p.88-179. (Coleção Os Pensadores).

BACHELARD, G. A água e os sonhos: ensaio sobre a imaginação da matéria. Trad. Antonio de P.Danesi. São Paulo: Martins Fontes, 1989a.

BACHELARD, G. Lautréamont. Trad. Maria Isabel Braga. Lisboa: Litoral Edições, 1989b.

BACHELARD, G. O direito de sonhar. 4. ed. Rio de Janeiro: Bertrand Brasil, 1994, p.v-xxi. BACHELARD, G. A poética do devaneio. Trad. Antonio de Pádua Danesi. São Paulo: Martins Fontes, 1996. 
FREIRE, P.Pedagogia da esperança: um reencontro com a pedagogia do oprimido. Rio de Janeiro: Paz e Terra, 1997.

JAPIASSU, H. Bachelard e a pedagogia das ciências. Revista Filosófica Brasileira, v.VI, n.1, p.4561, out. 1993.

JEAN, G. Bachelard, la infancia y la pedagogia. México: Fondo de Cultura Económica, 1989.

MAFFESOLI, M. O tempo das tribos. Trad. Maria de Lourdes Menezes. Rio de Janeiro: Forense Universitária, 1998.

NIETZSCHE, F. A Gaia ciência. Trad. Paulo César de Souza. São Paulo: Companhia das Letras, 2001.

NIETZSCHE, F. Zarathustra. Trad. Paulo César de Souza. São Paulo: Companhia das Letras, 2011.

PESSANHA, J. A. M. Introdução, Bachelard: as asas da imaginação. In: BACHELARD, G. O direito de sonhar. Rio de Janeiro: Bertrand Brasil, 1994, p.v-xxxi.

QUILLET, P.Introdução ao pensamento de Bachelard. Trad. César A. C. Fernandes. Rio de Janeiro: Zahar, 1977.

SILVA, L. B. O. Os complexos imaginários: imagens, estereótipos e obstáculos. Curitiba: CRV, 2013.

SILVA, L. B. O. Psicanálise, poética, epistemologia e educação: a contribuição de Gaston Bachelard. São Paulo: Editora Livraria da Física, 2018. 